\title{
The Role of Vessel Traffic Services in Traffic Separation Scheme
}

\author{
Indra Priyatna ${ }^{1}$, Antoine Gatinaud ${ }^{2}$ \\ ${ }^{I}$ Ministry of Transportation - Indonesia \\ ${ }^{2}$ Wartsila Voyage - France \\ Cyber Centre, No. $16 / 182^{\text {nd }} f l$ \\ Jalan Kilang Barat, Singapore 159358 \\ Tel. +65 6271 0200; Fax +65 62717300 \\ e-mail: indra.priyatna@multiintegra.co.id; antoine.gatinaud@wartsila.com
}

\begin{abstract}
The transportation of goods, passenger and livestock by sea is growing rapidly and rise a need for safety, security and environment protection. Now Indonesia is in the process of implementing E-Navigation. But since E-Navigation is complex and need a lot of system interoperability, then Indonesia may start the implementation by introducing VTS (Vessel Traffic Services) as a system designed to achieve the highest level of safety at sea, increase fleet efficiency and simplify everyday tasks both ashore and on board and therefore the operations are processed seamlessly, the compliance is guaranteed and the workload and costs are optimized. The VTS is not only for vessel traffic management but it also for harbour cluster and integrating communication system among stake holders on ships and on shore. But VTS plays a very important role in maintaining safety of navigation and efficiency as well as environment protection in traffic separation schemes. Nowadays, the next generation of VTS so-called smart VTS is capable to monitor (collect and process the data, create common operational picture, distribute data to clients), alerting (analyse traffic, detect dangerous traffic situations, and increase situation awareness), and respond (active decision support services and ensure ship to shore communications). The respond, however, is similar with the smart marine technology that may reduce human error significantly. Indonesia hopefully will implement the 16 kinds of MS (maritime services) portfolio with smart VTS especially in maintaining safety, security, efficiency and environment protection in traffic separation schemes.
\end{abstract}

Keywords : Role, Vessel Traffic Services (VTS)

\section{Introduction}

The transportation of goods by sea has supported world commerce for decades even centuries, giving rise to a need for ships to navigate safely and efficiently. Consequently, authorities throughout the world have provided aids to navigation in and around their coastal waters. The earliest aids to navigation were shore-side beacons and lights, followed by the introduction of buoys with audible signals.

However, it became clear that short range, audio-visual aids to navigation were insufficient to enable the full utilisation of port facilities in all conditions of visibility and increasing traffic density. Adverse weather and congestion resulted in delays of vessel traffic movement, which in turn created serious disruption to port operations with consequences for other modes of transport. Therefore, these aids to navigation were added 
with traffic monitoring using shore-based radar combined with communications that could enhance safety and efficiency in port areas and their approaches.

Later, number of shore-based radar sites were established around the world as well as in European ports.

Although these early systems were intended to minimise traffic delays and increase the efficiency of traffic flow in general, attention was also given to the number of shipping accidents and the ways in which these might be reduced. Studies were carried out to see what effect that vessel traffic services were having on reducing the number of accidents in port areas using radar surveillance. The studies concluded that, in addition to increasing the operational hours, thereby providing better utilisation of a port's capacity, the number of accidents was also being reduced.

Moreover, the ships disaster made the public aware of the environmental damage that a shipping accident could cause, and therefore there is a need to expand the use of radar surveillance and the management of vessel traffic.

In order to accommodate the need to expand the use of radar surveillance and the management of vessel traffic, the International Association of Marine Aids to Navigation and Lighthouse Authorities (IALA) Strategy established 14 priorities with a view to achieve two main goals, they are:

- Ensure that Aids to Navigation systems and related services, including e-Navigation, Vessel Traffic Services (VTS) and emerging technologies are harmonized through international co-operation and the provision of standards; and

- That all coastal states have contributed to an efficient global network of Aids to Navigation and services for the safety of navigation, through capacity building and the sharing of expertise.

In the implementation of VTS, IALA attaches great importance to its association with other maritime consultative bodies that participate in the work of the VTS Committee and who have played a key role in the development of guidance. These consultative bodies include the following international organizations:

- International Maritime Pilots' Association (IMPA);

- International Harbour Masters' Association (IHMA);

- International Federation of Shipmasters Associations (IFSMA);

- International Association of Ports and Harbours (IAPH); and

- The Nautical Institute (NI).

The following are idioms used in the implementation of VTS:

- Vessel traffic service (VTS) - a service implemented by a competent authority, designed to improve the safety and efficiency of vessel traffic and to protect the environment. The service should have the capability to interact with the traffic and to respond to traffic situations developing in the VTS area.

- Competent authority - the authority made responsible, in whole or in part, by the Government for safety, including environmental safety, and efficiency of vessel traffic and the protection of the environment.

- VTS authority - the authority with responsibility for the management, operation and coordination of the VTS, interaction with participating vessels and the safe and effective provision of the service.

- VT5 area - the delineated, formally declared service area of the VTS. A VTS area may be subdivided in sub-areas or sectors. 
It is prescribes in Internal Convention on Safety of Life at Sea (SOLAS) Annex B Chapter V-12 that when a VTS is being considered, care should be taken to establish the extent of jurisdiction that can be applied to the VTS area and its sub-areas or sectors, noting that participation is not mandatory outside of territorial waters.

With regard to the authority that may be given to a VTS, a State retains the right to control its territorial waters and all vessels that are subject to the jurisdiction of the State. Therefore, the authority to establish and operate VTS in a region is clearly established, including the right to mandate participation in a VTS scheme and to regulate a vessel's movements. Within territorial waters, a coastal State may exercise its authority subject to the right of innocent passage. Beyond territorial waters, a State's authority with regard to VTS is substantially reduced.

In straits used for international navigation, such as Malacca Strait, Sunda Strait and Lombok Strait, a VTS Authority cannot restrict or impede the innocent passage of vessels. In these instances, a State should endeavour to enter into agreements with neighbouring States, or other maritime nations, to agree standards of conduct for vessels operating in these waters. These standards may include provisions for voluntary participation in a VTS or the requirements of an internationally agreed Ship Reporting System (SRS).

The good example is that the International Maritime Organization (IMO) has adopted the joint-proposal by Indonesia, Malaysia and Singapore to introduce a mandatory ship reporting system in the Straits of Malacca and Singapore. The ship reporting system, known as STRAITREP, was adopted at the $69^{\text {th }}$ session of the IMO's Maritime Safety Committee (MSC 69) and implemented commenced on 1 December 1998 while the conduct of Ship Reporting System (SRS) from Port Klang, Malaysia to Singapore are divided into 9 (nine) sectors. Consequently, all ships passing Malacca Strait shall submit their SRS to VTS station provided by the VTS authority.

\section{Research Method}

Method of research is qualitative and combine with meta-analysis method by collecting data and information concerning implementation of E-Navigation especially in the implementation of Vessel Traffic Services in Finland, Denmark, Sweden, Turkey, Straits of Malacca and Singapore in conjunction with the role of VTS in the management of traffic separation scheme.

Since the first author is expert on smart port and Fleet Operations Solution (FOS) including the use of smart VTS as a system designed to achieve the highest level of safety at sea, increase fleet efficiency and simplify everyday tasks both ashore and on board and therefore the operations are processed seamlessly, the compliance is guaranteed and the workload and costs are optimized, while the second author is expert on maritime affair that was involved in the study for the implementation of E-Navigation in Indonesia, then the approach of research is observation participatory.

\section{Results and Analysis}

Vessel traffic service (VTS) is a service implemented by a competent authority, designed to improve the safety and efficiency of vessel traffic and to protect the environment. The service should have the capability to interact with the traffic and to respond to traffic situations developing in the VTS area by using radio communication and related electronic means within the VTS coverage area. 
According to Annex B, Internal Convention on Safety of Life at Sea (SOLAS) Annex B Chapter V regulation 12, the provision of Vessel Traffic Services as the following:

1. Vessel Traffic Services (VTS) contribute to safety of life at sea, safety and efficiency of navigation and protection of the marine environment, adjacent shore areas, work sites and offshore installations from possible adverse effects of maritime traffic;

2. Contracting Governments undertake to arrange for the establishment of VTS where, in their opinion, the volume of traffic or the degree of risk justifies such services;

3. Contracting Governments planning and implementing VTS shall, wherever possible, follow the guideline developed by the Organization. The use of VTS may only be made mandatory in sea areas within the territorial seas of a coastal State;

4. Contracting Governments shall endeavour to secure the participation in, and compliance with, the provisions of vessel traffic services by ships entitled to fly their flag;

5. Nothing in this regulation or the guidelines adopted by the Organization shall prejudice the rights and duties of Governments under international law or the legal regimes of straits used for international navigation and archipelagic sea lanes.

Refer to the Guidelines on VTS adopted by IMO Resolution A.857(20), the purpose of the VTS are:

1. The purpose of vessel traffic services is to improve the safety and efficiency of navigation, safety of life at sea and the protection of the marine environment and/or the adjacent shore area, worksites and offshore installations from possible adverse effects of maritime traffic.

2. A clear distinction may need to be made between a Port or Harbour VTS and a Coastal VTS. A Port VTS is mainly concerned with vessel traffic to and from a port or harbour or harbours, while a Coastal VTS is mainly concerned with vessel traffic passing through the area. A VTS could also be a combination of both types. The type and level of service or services rendered could differ between both types of VTS; in a Port or Harbour VTS a navigational assistance service and/or a traffic organization service is usually provided for, while in a Coastal VTS usually only an information service is rendered.

3. The benefits of implementing a VTS are that it allows identification and monitoring of vessels, strategic planning of vessel movements and provision of navigational information and assistance. It can also assist in prevention of pollution and coordination of pollution response. The efficiency of a VTS will depend on the reliability and continuity of communications and on the ability to provide good and unambiguous information. The quality of accident-prevention measures will depend on the system's capability of detecting a developing dangerous situation and on the ability to give timely warning of such dangers.

4. The precise objectives of any vessel traffic service will depend upon the particular circumstances in the VTS area and the volume and character of maritime traffic as set forth in the Guidelines and Criteria.

The implementation of VTS in the traffic separation schemes will significantly increase the level of safety and security as well as the marine environmental protection. 
The different of straits management without and with VTS for example at Sunda Strait could be seen in the following figure:

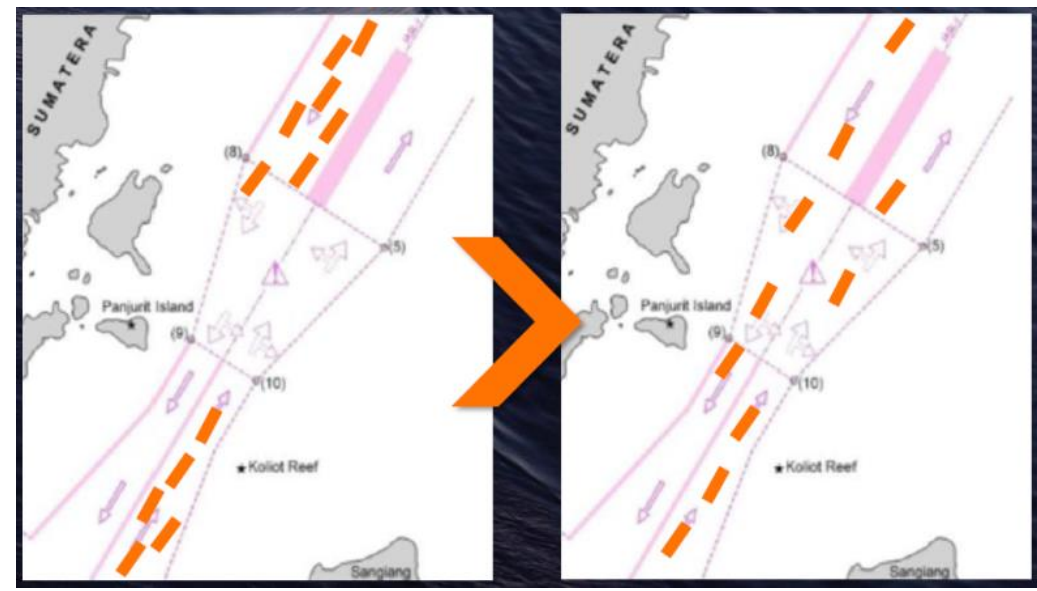

Figure-1 Optimization of Traffic Flow with VTS

Furthermore, according IALA Guideline 1089 Provision of VTS services, there are 3 kind of services offered by the VTS station, i.e.:

1. INS is a service to ensure that essential information becomes available in time for on board navigational decision-making;

2. TOS is a service to prevent the development of dangerous maritime traffic situations and to provide for the safe and efficient movement of vessel traffic;

3. NAS is a service that provides essential and timely navigational information to assist in the on board navigational decision-making process and to monitor its effects.

However, as time goes by, IALA hosted a seminar on the revision of IMO Resolution A.857(20) Guidelines for Vessel Traffic Services from 26 to 27 June 2019. The seminar was held at IALA Headquarters attended by stakeholders with an interest in Vessel Traffic Services (VTS).

The seminar was attended by 77 participants, representing 25 countries and 7 sister organizations.

The revision is less prescriptive in line with a modern approach, more suitable for a rapidly changing world, references IALA VTS standards, avoids previous ambiguity and is a forward-looking document. During the seminar that $96 \%$ of participants agreed that the concept of types of service (INS, TOS and NAS) was confusing and unnecessary. Moreover, there is no need to distinguish between port and coastal VTS.

As a result of the above seminar, the following guidance concerning the services that are rendered by a VTS should be taken into account:

1. The information service is provided by broadcasting information at fixed times and intervals or when deemed necessary by the VTS or at the request of a vessel, and may include for example reports on the position, identity and intentions of other traffic; waterway conditions; weather; hazards; or any other factors that may influence the vessel's transit.

2. The navigational assistance service is especially important in difficult navigational or meteorological circumstances or in case of defects or deficiencies. This service is normally rendered at the request of a vessel or by the VTS when deemed necessary. 
3. The traffic organization service concerns the operational management of traffic and the forward planning of vessel movements to prevent congestion and dangerous situations, and is particularly relevant in times of high traffic density or when the movement of special transports may affect the flow of other traffic. The service may also include establishing and operating a system of traffic clearances or VTS sailing plans or both in relation to priority of movements, allocation of space, mandatory reporting of movements in the VTS area, routes to be followed, speed limits to be observed or other appropriate measures which are considered necessary by the VTS authority.

4. When the VTS is authorized to issue instructions to vessels, these instructions should be result-oriented only, leaving the details of execution, such as course to be steered or engine manoeuvres to be executed, to the master or pilot on board the vessel. Care should be taken that VTS operations do not encroach upon the master's responsibility for safe navigation, or disturb the traditional relationship between master and pilot.

5. A VTS area can be divided into sectors, but these should be as few as possible. Area and sector boundaries should not be located where vessels normally alter course or manoeuvre or where they are approaching areas of convergence, route junctions or where there is crossing traffic. VTS centres in an area or sector should use a name identifier. The boundaries should be indicated in the appropriate nautical publications and in the "World VTS Guide".

\subsection{Result of Feasibility Study}

The implementation of e-Navigation especially in the operation of VTS station in Denmark is operated by Danish Navy and therefore it is not suitable for Indonesia. But the concept of implementation of E-Navigation especially for Smart VTS in Sweden i.e., Port of Gothenburg is similar with the smart VTS in Finland since they are implementing the same system which is develop by Wärtsilä.

On the other hand, the concept of sea transportation traffic management in Turkey (IALA Vessel Traffic Services Manual, $6^{\text {th }}$ Edition, 2016 Annex E) to some extent has similarity with the Marine Electronic Highway in the Strait of Malacca and Singapore that might be consider in the discussion.

Furthermore, the discussion over the conference is to introduce the use of VTS as the most powerful tools in the implementation of E-Navigation in Indonesia especially in the implementation of VTS at Lombok Strait and Sunda Straits.

Vessel Traffic Services implemented by a Competent Authority are subject to IMO Member State Audit Scheme (IMSAS). All IMO audits from 1 January 2016 are mandatory and should be arranged and carried out in line with the framework and procedures for the IMO Member State Audit Scheme, using the IMO Instruments Implementation Code (III Code) as the audit standard.

IALA has developed Guideline No. 1115 on 'Preparing for IMO Member State Audit Scheme (IMSAS) On Vessel Traffic Services' in order to provide guidance for Contracting Governments and Competent Authorities to meet the objectives of an IMO Member State Audit Scheme (IMSAS) with respect to the implementation and delivery of VTS and to demonstrate they are fulfilling their responsibilities under the general provisions of treaty law and IMO conventions for promulgating laws and regulations. They are also responsible for taking all other steps which may be necessary to give full and 
complete effect to SOLAS Chapter V (Safety of Navigation) Regulation 12 (Vessel Traffic Services).

Since IALA is committed to the provision of high-quality services and encourages navigation authorities to adopt internationally recognised standards for the management and delivery of services as set out in IALA Recommendation O-132 - 'Quality Management for Aids to Navigation Authorities'. Then any coastal state including the Government of Indonesia shall pay a close attention to this IALA Recommendation O-132 amongst other things covers:

- Authorities responsible for aids to navigation, implement and maintain a Quality Management System (QMS);

- Authorities ensure the ongoing integrity of the QMS through periodic:

1) Certification by an accredited third party; and/or

2) Assessment by a third party; and/or

3) Self-assessment.

Action in a Traffic Organization Service amongst other things covers

- Traffic clearance: Give authorization under conditional circumstances to a vessel when departing from a berth or an anchorage;

- Anchorage: Assignment of an anchorage position

- Enforcement: Adherence to rules regarding traffic routing measures;

- Waterway management: Slot management to allocate ships in a time window, and instruct vessels when overtaking is not permitted.

Implementation of Vessel Traffic Service in the Gulf of Finland is to face challenges such as dense ship traffic in the Gulf in constant increase of heavy tankers coming from Russian ports and therefore creation of a TSS (Traffic Separation Scheme) and Mandatory Ship Reporting System (GOFREP) is needed to monitor adherence to applicable rules and regulations as well as take appropriate action where required for 24 hours in 7 days a week.

The solution for these challenges is to develop regional VTS to manage the TSS by integrating remote posts sensors (AIS base stations and radars) as well as integration of databases within the GOFREP project.

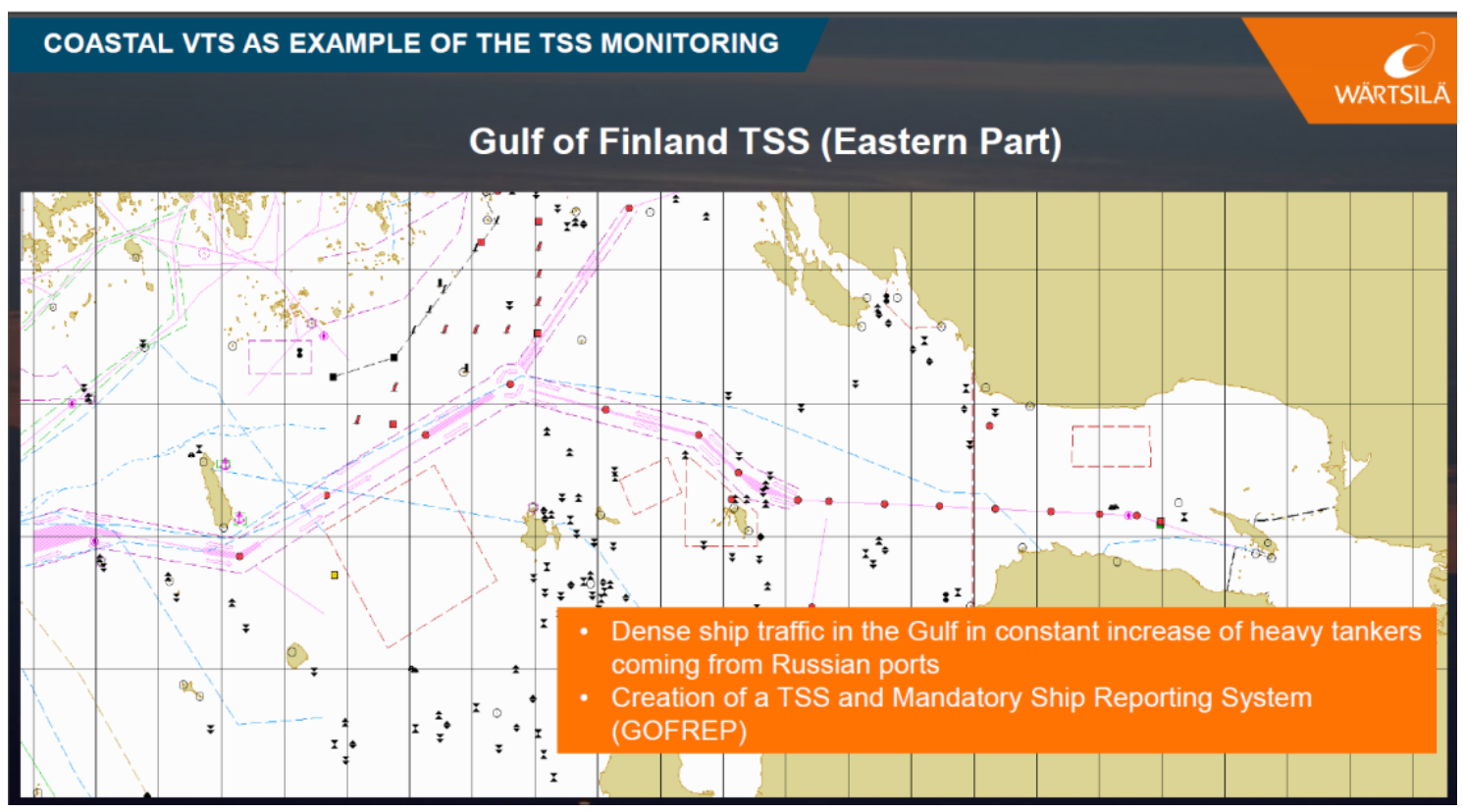

Figure-2 VTS in Gulf of Finland

This paper is presented in The $4^{\text {th }}$ International Conference on Maritime Education and Training 16 October $8^{\text {th }}$,2020, Makassar, Indonesia 
The reason of promoting the GOFREP project is not only that the head quarter of Wärtsilä is in Finland, but considering the fact that the European Union has already introduced the implementation of E-Navigation through four phases i.e., Monalisa 1.0 conducted between year 2010 to 2013, Monalisa 2.0 conducted between year 2013 to 2015, STM (Sea Traffic Management) Efficiency-1 and STM Efficiency-2 conducted between year 2015 to 2018. And now the implementation of Smart VTS is progressing and hopefully Indonesia could get benefit from the experience of particular country.

\subsection{Analysis}

Based on explanation above and the necessity of Indonesian Government in the implementation of E-Navigation, we can conclude that the priority for the development of Indonesian E-Navigation may be divided into 3 stages as follows:

1) At the first stage, Indonesian E-Navigation could be developed by developing Smart VTS whereas the VTS is designed to ease the operator in operating VTS equipment with the following concept:

a) Modular: to ease the operator on isolation, update, restart, maintenance, and upgrade the system;

b) Advance Communication, using voice, text (written communication), phone, radio, e-mail, and safety information broadcast are all in one integrated information basis;

c) Advance Sensor Systems, using radar, AIS, Optical, Satellite, Weather information, and Long-Range Identification and Tracking;

d) Dissemination of information easily, effective and scheduled;

e) Smart Collaboration: vertically among VTS centre, pilot centre, harbour offices i.e., harbour masters (KSOP and UPP), Pelindo (Indonesian Port State-owned Company), port private-owned companies, police, security agency and coast guard), etc., while horizontally is among VTS stations;

f) Smart Monitoring: automatic message to avoid human error and reducing the possibility of ships collision, grounding and other disaster including the protection of marine environment.

The link of communication between the ship side and the shore side can be seen in the following figure: 


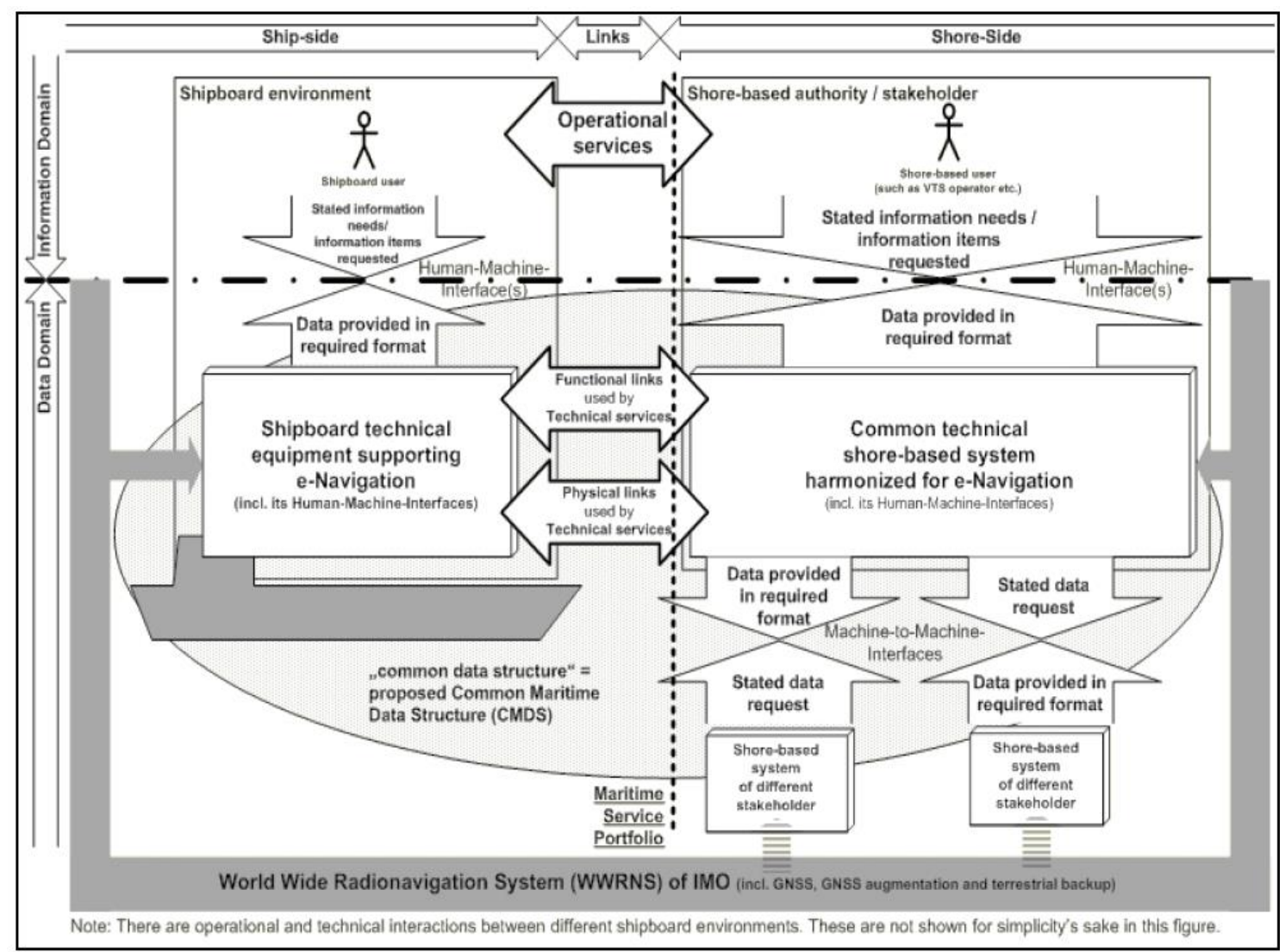

Figure-3 E-Navigation Architecture

2) At the second stage, based on IMO MSC.1/Circ.1595 (99) concerning renewal (update) 1 E-Navigation Strategy Implementation Plan (SIP), there are 16 kinds of MS (maritime services) portfolio, whereas distribution of services to relevant stakeholder in Indonesia will be as follow.

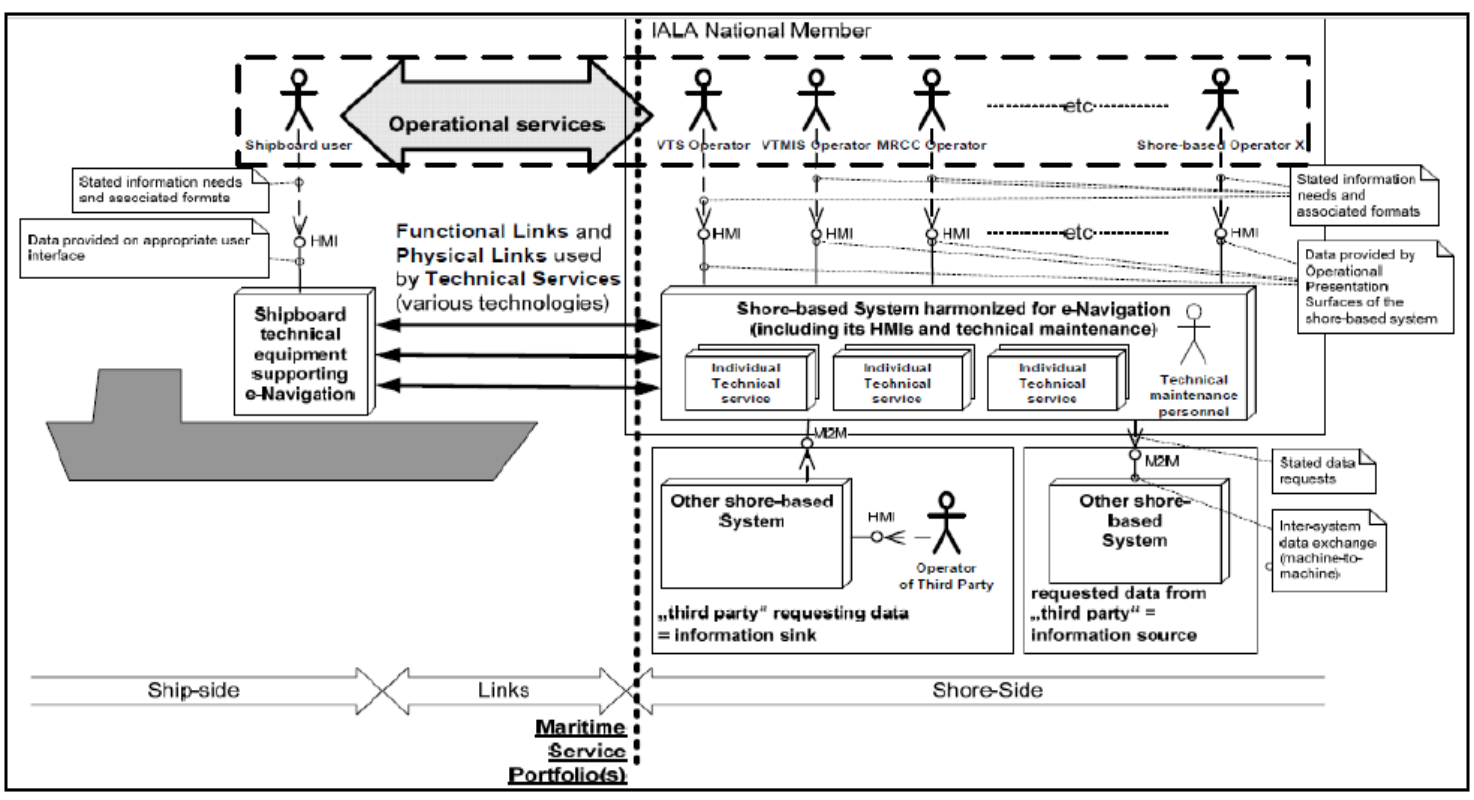

Figure-4 Shore Side E-Navigation Architecture

This paper is presented in The $4^{\text {th }}$ International Conference on Maritime Education and Training 
The breakdown of those $16 \mathrm{MS}$ portfolios will be more or less as follows:

a) VTS portfolio category MS-01 to MS-03, MS-05 and MS-08, they are:

- MS-01: VTS Information Service (INS)

- MS-02: Navigational Assistance Service (NAS)

- MS-03: Traffic Organization Service (TOS)

- MS-05: Maritime Safety Information (MSI)

- MS-08 Vessel Shore Reporting;

b) PELINDO (Indonesian Port State-owned Company) and private-owned port companies portfolio category MS-04, MS-06 and MS-07, they are:

- MS-04: Local Port Service (LPS)

- MS-06: Pilotage Service

- MS-07: Tug Service;

c) Shipping Company portfolio category MS-08: Vessel Shore Reporting;

d) Port Health Centre and PMI (Indonesian Red Cross) portfolio category MS-09 Telemedicine Assistance Service (TMAS);

e) KSOP (Harbour Master) and KPLP (Coast Guard) portfolio category MS-10 Maritime Assistance Service (MAS);

f) PUSHIDROSAL (Centre of Indonesian Navy Hydrographic Office) portfolio category MS-11, MS-12 and MS-15 as they are:

- MS-11: Nautical Chart Service

- MS-12: Nautical Publication Service

- MS-15: Real-time hydrological and Environmental Information Service

g) BMKG (Indonesian Meteorological and Geophysics Agency) portfolio category MS14: Meteorological Information Service;

h) BASARNAS (Indonesian Search and Rescue Agency) portfolio category MS-16 Search and Rescue Service;

i) Portfolio category MS-13: Ice Navigation Service is not available in Indonesian waters.

3) The $3^{\text {rd }}$ stage is to integrate the whole strategic plan, i.e., the conduct of test bed, bathymetry of ENC (electronic navigational chart), instalment of AIS (Automated Identification System) base in Indonesian navigable waters, maintaining the implementation of LRIT (Long Range Identification Tracking), VMS (Vessel Monitoring System), National Single Window (NSW) reporting port cooperation with $\mathrm{XYZ}$ approach, pilotage, search and rescue, etc., and monitoring the system with the next generation of VTS including alerting prior to respond the incoming data and information.

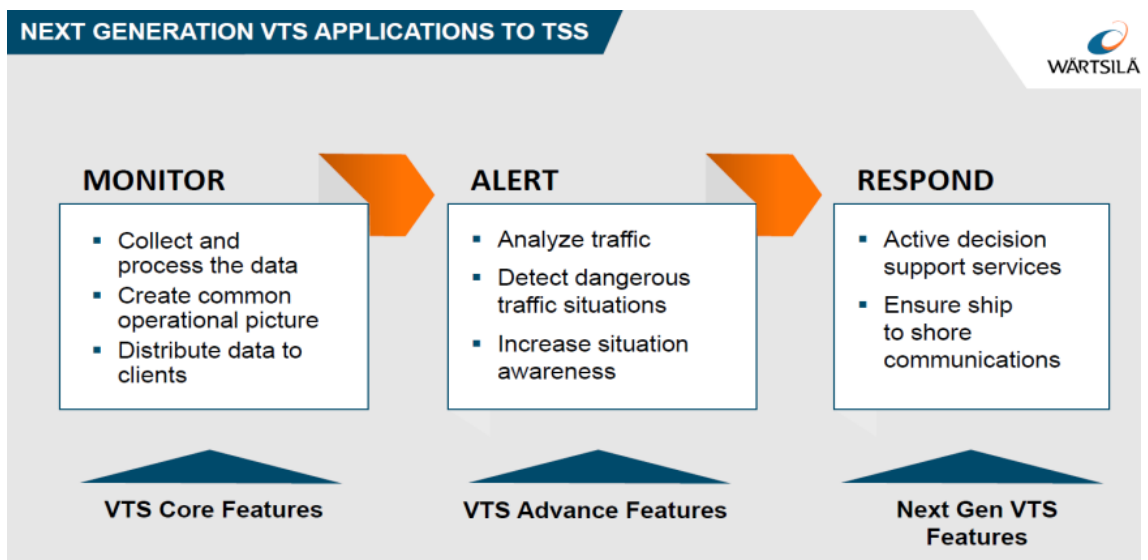

Figure-5 Scheme of Next Generation VTS 
But creating a common situational awareness for ship routing based on ocean passage of the world is not that simple since there are different between the strait management and the harbour management. The harbour cluster is focused on vessel ETD (estimate time of departure) to obtain the precise JIT (just in time) of vessel ETA (estimate time of arrival) which required several system interoperability.

Therefore, the fastest way to start implementation of E-Navigation in Indonesia is by implementing the smart VTS as shown in figure 6 .

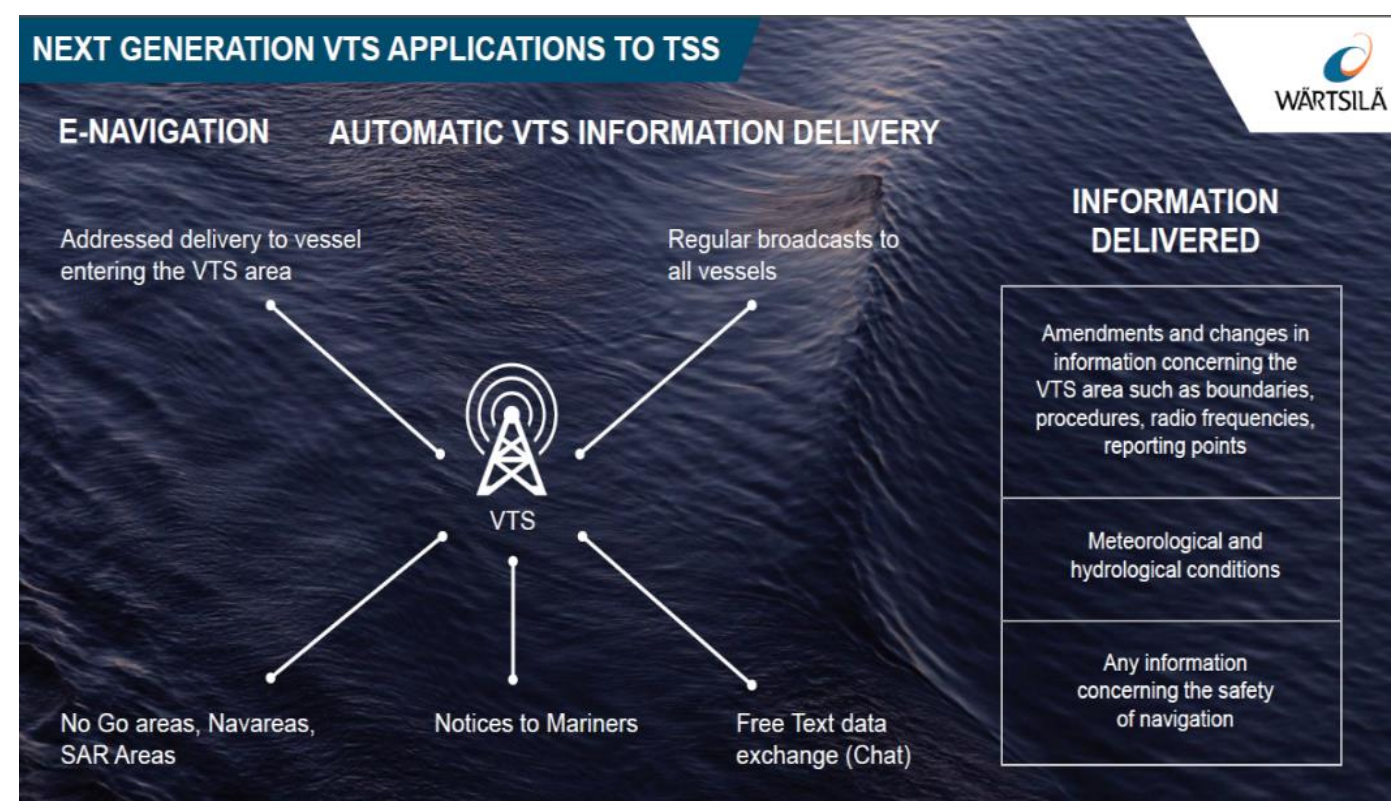

Figure-6 Scheme of Smart VTS

\section{Conclusion}

1) VTS is a service implemented by a Competent Authority, designed to improve the safety and efficiency of vessel traffic and to protect the environment. It should have the capability to interact with the traffic and respond to traffic situations developing in the area.

2) Particularly TSS is relevant for area with high traffic density whereas vessel movements may affect the traffic flow.

3) Traffic Organization Service will be provided when we need planning of vessel movements to prevent congestion or dangerous situations, organizing of special transports of vessels with hazardous cargo, establishing of the system of traffic clearances, organizing of the allocation of space, establishing of mandatory reporting movements, following of special routes, and observing of speed limits of vessels.

4) In the implementation of E-Navigation especially in traffic flow optimization at Sunda Strait and Lombok Strait, the use of Smart VTS is addressed to foresee dense traffic situations in challenging navigation area, optimal coordination of multiple ships, and assign slots for vessels passing the TSS.

5) The implementation of E-Navigation is complicated and therefore the fastest way to start the implementation is by implementing the smart VTS. 


\section{References}

[1] Y.V. Aydogdu, E. Yalcin \& C. Yurtorren, A Discussion on e-Navigation and Implementation in Turkey, in the International Journal on Marine Navigation and Safety of Sea Transportation No.1, Vol.8, 2014, page 81.

[2] Wan Siti Adibah Wan Dahalan at al., E-Navigation in the Straits of Malacca and Singapore, In International Journal of Computer Theory and Engineering, Vol. 5, No. 3, June 2013,pages 388.

[3] IMO, Maritime Safety Committee Resolution 85/26/Add.1 Annex 20, Strategy for the Development and Implementation of E-Navigation.

[4] IMO, Elemen E-Nav, MSC 85/26/Add.1 Annex 20, 2008

[5] IALA, Vessel Traffic Services Manual, $6^{\text {th }}$ Edition, 2016, page 27, 36 and 42

[6] IALA, Strategic Plan, IALA Vision for E-Navigation, Nordic Navigation Conference, 2007

[7] Steps to Implement, MSC 85/26/Add.1 Annex 20, 2008

[8] E-Nav Solution, NCSR 1/28 Annex 7, 2014

[9] Danish Maritime Authority, e-Navigation Underway 2019 / International, International e-Navigation Underway 2019 Conference Report to IALA, 2019.

[10] PT. Artha Demo Engineering Consultant, Studi Penerapan E-Navigation Indonesia (Study on the Implementation of Indonesian E-Navigation), 2019, page III-1, III-2, IV- 33,

[11] Wärtsilä, Ship Traffic Control Solutions, Transas e-Navigation Project, 2019.

\section{Index of Figure}

Figure-1: Optimization of traffic flow with VTS

Figure-2: VTS in Gulf of Finland

Figure-3: E-Navigation Architecture

Figure-4: Shore Side E-Navigation Architecture

Figure-5: Scheme of Next Generation VTS

Figure-6: Scheme of Smart VTS 